\title{
Medication adherence and its associated factors among hypertensive patients attending the Debre Tabor General Hospital, northwest Ethiopia
}

\author{
Destaw Fetene Teshome' \\ Kindie Bantie Bekele' \\ Yohannes Ayanaw Habitu ${ }^{2}$ \\ Abebaw Addis Gelagay ${ }^{2}$ \\ 'Department of Epidemiology \\ and Biostatistics, ${ }^{2}$ Department of \\ Reproductive Health, Institute of \\ Public Health, University of Gondar, \\ Gondar, Ethiopia
}

This article was published in the following Dove Press journal:

Integrated Blood Pressure Control

16 June 2017

Number of times this article has been viewed

Background: Medication adherence is an important predictor of optimal blood pressure control; hence, it significantly reduces the risk of cardiovascular disease (CVD) and associated deaths. However, studies on medication adherence and its associated factors are scarce. Thus, this study aimed to assess adherence to antihypertensive medications and identify associated factors at Debre Tabor General Hospital, northwest Ethiopia.

Methods: A hospital-based cross-sectional study was conducted. Simple random sampling technique was used to select 346 participants. A structured questionnaire adapted from the World Health Organization (WHO) STEPwise approach was used to collect data. Medication adherence was measured by the four-item Morisky-Green-Levine Scale, with a score $\geq 3$ defined as "good adherence". Data were entered using Epi Info version 7 and exported to SPSS version 20 for analysis. Descriptive and summary statistics were used. Bivariate and multivariable analyses were also carried out.

Results: A total of 337 hypertensive patients participated in the study. Three-quarters $(75.1 \%)$ of the participants were found to be adherent to their medication therapy. The multivariable logistic regression analysis showed that urban residence (adjusted odd ratio [AOR] $=2.10,95 \%$ confidence interval $[\mathrm{CI}]: 1.15,3.85)$, taking less than two drugs per day (AOR=3.04, 95\% CI: $1.53,6.06)$, and having knowledge about hypertension $(\mathrm{HTN})$ and its treatment $(\mathrm{AOR}=8.86$, 95\% CI: 4.67, 16.82) were positively and significantly associated with medication adherence, while age $>60$ years (AOR=0.33, 95\% CI: $0.11,0.98$ ) was negatively and significantly associated with good medication adherence.

Conclusion: A significant proportion of hypertensive patients poorly adhere to antihypertensive medications. Age, residence, pill burden, and knowledge about HTN and its treatment are important predictors of medication adherence. Attention should be given to increase the knowledge of patients about their disease and its treatment, and due emphasis should also be given to older and rural patients.

Keywords: hypertension, adherence, Morisky-Green-Levine Scale

\section{Introduction}

Hypertension (HTN), known as high blood pressure (BP), is one of the major but modifiable risk factors of cardiovascular disease (CVD)-related morbidities and mortalities. $^{1,2}$ It is a global public health issue affecting nearly one billion people ${ }^{2-4}$ and is estimated to increase to 1.56 billion adults by the year 2025 , with two-thirds in developing countries. ${ }^{4,5}$ The age-adjusted prevalence of HTN is the highest in the African region, with $30 \%$ of adults aged 18 years and older were affected. ${ }^{6}$ Currently, HTN is the second most important preventable risk factor of premature deaths contributing to
Correspondence: Destaw

Fetene Teshome

Department of Epidemiology and Biostatistics, Institute of Public Health, University of Gondar, Gondar 196, Ethiopia

Mob +25I 918037193

Email destaw.fetene@gmail.com
Integrated Blood Pressure Control 2017:10 I-7

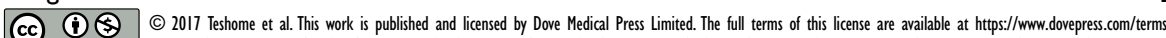
php and incorporate the Creative Commons Attribution - Non Commercial (unported, 33.0 ) License (http://creativecommons.org/licenses/by-nc/3.0). By accessing the work you herbby accept the Terms. Non-commercial uses of the work are permitted without any further permission from Dove Medical Press Limited, provided the work is properly attributed. For permission for commercial use of this work, please see paragraphs 4.2 and 5 of our Tems (https://www.doveperess.com/terms.php. 
$13 \%$ of global deaths. ${ }^{7}$ Of the 17 million deaths due to CVD worldwide, complication of HTN accounts for 9.4 million every year. It is also responsible for at least $45 \%$ of deaths due to heart disease and $51 \%$ of deaths due to stroke. ${ }^{8}$ In Ethiopia, $3.5 \%$ of all deaths are due to HTN, making it the seventh leading cause of death in the country. ${ }^{9}$

Antihypertensive medication is one of the measures to manage HTN to an optimal BP control level. ${ }^{10}$ Medication adherence, which significantly reduces the risk of CVD and associated deaths, ${ }^{4,5}$ is a very important predictor of optimal BP control. ${ }^{11-13} \mathrm{BP}$ control among hypertensive patients is poor in Sub-Saharan Africa, ${ }^{14-16}$ and evidence suggests that medication nonadherence is a potential modifiable risk factor for poor BP control. ${ }^{17,18}$

Although a number of studies have shown the prevalence of, and factors associated with, HTN in Ethiopia, ${ }^{19-22}$ there is limited information about the level of medication adherence and its associated factors in the study area. Therefore, the aim of this study was to assess antihypertensive medication adherence and associated factors among hypertensive patients attending the Debre Tabor General Hospital, northwest Ethiopia.

\section{Methods}

\section{Study design and setting}

A hospital-based cross-sectional study was conducted from March to May 2015 at Debre Tabor General Hospital, northwest Ethiopia. The hospital is located in Debre Tabor town, the South Gondar Zone of the Amhara National Regional State, $667 \mathrm{~km}$ from Addis Ababa. It is the only general hospital providing both curative and preventive health care services to $\sim 2.3$ million people in the zone and nearby districts. It has a capacity of 91 beds for inpatient services in five disciplines and 12 outpatient departments (OPDs). The hospital has specialty chronic illness clinics where patients with specific chronic diseases are referred for follow-up. In this clinic, physicians give services to $\sim 10-40$ hypertensive patients a day during working hours.

All hypertensive patients aged 18 years and older who were on antihypertensive treatment for at least 3 months before the study period and were on follow-up from March to May 2015 were included in the study.

\section{Sample size and sampling procedure}

The sample size was determined by using the single population proportion formula, assuming a 95\% confidence interval (CI), a prevalence of $69.2 \%$ for good adherence, ${ }^{23} \mathrm{a}$ $5 \%$ margin of error, and a 5\% nonresponse rate. The simple random sampling technique was used to select 346 study participants after obtaining patient list from Chronic Illness Clinic Registration Book.

\section{Data collection tools and procedures}

A pretested structured questionnaire adopted from the World Health Organization (WHO) STEPwise approach to surveillance of non-communicable diseases, including sociodemographic characteristics, medication-related factors, behavioral and life style factors, comorbidities, ${ }^{24}$ and the Morisky-Green-Levine Scale, ${ }^{25-27}$ was used to collect data.

The questionnaire was first prepared in English and then translated into the local language (Amharic). Four professionals trained for 2 days collected the data using the intervieweradministered questionnaire. Moreover, to ascertain BP control, the data collectors reviewed patients' charts and took three BP measurements over the preceding 3 months. The principal investigator and the supervisor closely monitored the data collection process by making telephone contact and solving problems on a daily basis. Coding and data cleaning were done (checking frequencies and cross-tabs for each item).

The Morisky-Green-Levine Scale, a four-item self-report measure of medication-taking behavior, which has high reliability and validity, was used for assessing patient adherence. It measures both intentional and unintentional adherence based on forgetfulness, carelessness, stopping medication when feeling better, and stopping medication when feeling worse. Response categories were either yes or no for each item. In all, 0 point was allocated to a yes response and 1 point to a no response. The total score ranged from 0 (nonadherent) to 4 (adherent). The results were scored for all questions of medication adherence with a score of $\geq 3$ classified as "having good adherence".

\section{Operational definitions}

Controlled BP was defined as the achievement of an average three BP readings $<140 / 90 \mathrm{mmHg}$ for age $<60$ years and $<150 / 90 \mathrm{mmHg}$ for age $\geq 60$ years in individuals being treated for HTN. ${ }^{5}$

Knowledge about HTN and its treatment was assessed using six-item questions and computing by taking the mean value. Respondents who scored above the mean for the knowledge questions were classified as having good knowledge.

Patients were defined as having moderate level of physical activity if they performed $\geq 3$ days of vigorous intensity activity for at least 20 minutes/day, $\geq 5$ days of moderate intensity activity, or walking for at least 30 minutes/day. 
The number of prescribed oral medications was defined as all types of oral medications, including antihypertensive and non-antihypertensive medications, taken on a regular basis and prescribed by health care providers.

Smokers were defined as participants who smoked at least one cigarette per day at the time of the study.

\section{Data processing and analysis}

Data were entered using Epi Info version 7, analyzed using SPSS version 20, were checked and cleaned for completeness and consistency of values and variables, computed for calculable variables, and recoded. Descriptive and summary statistics were used. Bivariate analysis was done to check which variables had associations with good medication adherence. Variables with $p$-values up to 0.2 in the bivariate analysis were fitted in the multivariable logistic regression for controlling possible effects of confounders. The Hosmer and Lemeshow goodness of fit test for the model was also checked. Finally, the variables that had significant associations with good medication adherence were identified on the basis of the odds ratio (OR) with a $95 \% \mathrm{CI}$ and $p$-values $<0.05$.

\section{Ethical approval and consent}

Ethical clearance was obtained from the ethical review board of the Institute of Public Health, College of Medicine and Health Sciences, University of Gondar. A permission letter was also obtained from Debre Tabor General Hospital.

Informed verbal consent was obtained from each study participant, and participant involvement in the study was voluntary. Confidentiality of data was guaranteed by using identification numbers rather than names and limiting access to the data.

\section{Results}

\section{Sociodemographic characteristics of participants}

A total of 337 hypertensive patients participated in this study, giving a response rate of $97.4 \%$. The mean age of the participants was 58.3 years ( $\mathrm{SD}=13.7$ years), ranging from 23 to 88 years. Out of the total participants, 174 (51.6\%) were females, $333(98.8 \%)$ were from the Amhara ethnic group, and 321 (95.2\%) were Orthodox Christians. Two-thirds of the participants $(66.2 \%)$ were married, and $233(69.1 \%)$ were urban dwellers. Of the participants, 74 (71.2\%) rural dwellers and 87 (37.4\%) urban dwellers were illiterate (Table 1).
Table I Sociodemographic characteristics of participants ( $N=337)$, Debre Tabor General Hospital, 2015

\begin{tabular}{|c|c|c|}
\hline Variable & Frequency & Percent \\
\hline \multicolumn{3}{|l|}{ Sex } \\
\hline Male & 163 & 48.4 \\
\hline Female & 174 & 51.6 \\
\hline \multicolumn{3}{|l|}{ Age (years) } \\
\hline $18-40$ & 35 & 10.4 \\
\hline $4 I-60$ & 161 & 47.8 \\
\hline$\geq 61$ & $|4|$ & 41.8 \\
\hline \multicolumn{3}{|l|}{ Residence } \\
\hline Urban & 233 & 69.1 \\
\hline Rural & 104 & 30.9 \\
\hline \multicolumn{3}{|l|}{ Ethnic group } \\
\hline Amhara & 333 & 98.8 \\
\hline Others ${ }^{\mathrm{a}}$ & 4 & 1.2 \\
\hline \multicolumn{3}{|l|}{ Religion } \\
\hline Orthodox & 321 & 95.2 \\
\hline Others $^{\mathrm{b}}$ & 16 & 4.8 \\
\hline \multicolumn{3}{|l|}{ Marital status } \\
\hline Single & 7 & 2.1 \\
\hline Married & 223 & 66.2 \\
\hline Divorced & 33 & 9.8 \\
\hline Widowed & 70 & 20.8 \\
\hline Separated & 4 & 1.2 \\
\hline \multicolumn{3}{|l|}{ Educational status } \\
\hline Unable to read and write & 161 & 47.8 \\
\hline Able to read and write & 49 & 14.5 \\
\hline Primary school & 45 & 13.4 \\
\hline Secondary and high school & 24 & 7.2 \\
\hline College/university completed & 58 & 17.2 \\
\hline \multicolumn{3}{|l|}{ Occupational status } \\
\hline Housewife & 109 & 32.3 \\
\hline Farmer & 82 & 24.3 \\
\hline Government employed & 63 & 18.7 \\
\hline Merchant & 28 & 8.3 \\
\hline No job & 22 & 6.5 \\
\hline Retired & 19 & 5.6 \\
\hline Others ${ }^{c}$ & 7 & 2.1 \\
\hline \multicolumn{3}{|l|}{ Monthly family income (ETB) ${ }^{d}$} \\
\hline$<358$ & 85 & 25.2 \\
\hline $358-640$ & 85 & 25.2 \\
\hline $641-1525$ & 85 & 25.2 \\
\hline$>1,525$ & 82 & 24.4 \\
\hline
\end{tabular}

Notes: ${ }^{a}$ Tigre and Agew. 'Muslim and Adventist. 'Students, nongovernmental organization workers, and daily laborers. Income is categorized based on quartiles. Abbreviation: ETB, Ethiopian Birr.

\section{Lifestyle and behavioral characteristics of participants}

The vast majority, $329(97.6 \%)$ and $98(29.1 \%)$ of the participants were eating cereal products and vegetables, respectively, on most days of the week. A total of 215 (63.8\%) participants were using sesame oil for their usual meal preparations, and 109 (32.3\%) of the participants used additional salt when cooking or preparing food at home. 
Among participants, only five (1.3\%) were found to be smokers and 40 (11.9\%) drank alcohol daily. Regarding patients' physical activity, 155 (46\%) of the respondents were classified as having moderate levels of physical activity.

\section{Comorbidity-related characteristics of the respondents}

Out of the total participants, $65(19.3 \%)$ had diabetes mellitus, 56 (16.6\%) had CVDs, 26 (7.7\%) had asthma, and 23 (6.8\%) had chronic kidney disease (Figure 1).

\section{Medication-related characteristics of participants}

Among the participants, 225 (66.8\%) were taking two or more drugs per day, 262 (77.7\%) had good knowledge of HTN and its treatment, and the overall proportion with optimally controlled BP was $42.4 \%$ (Table 2).

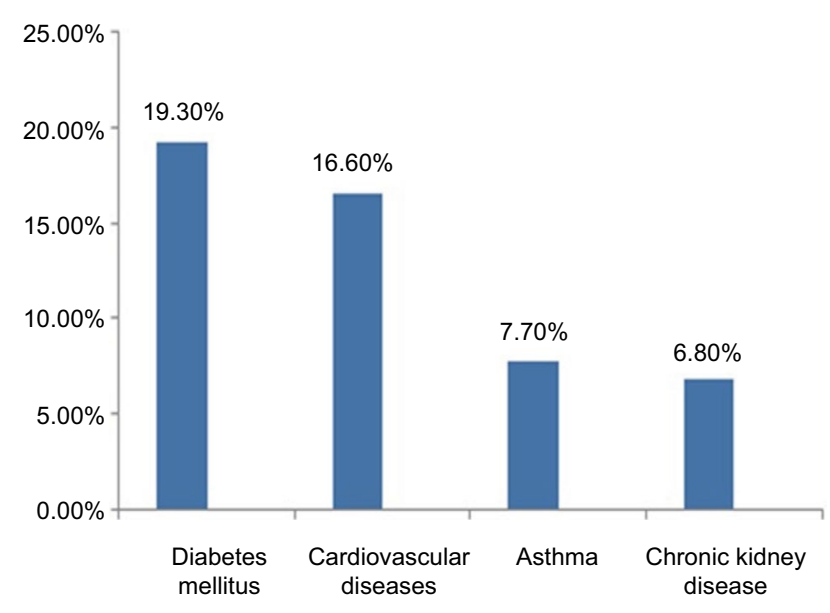

Figure I Comorbidity-related characteristics of the participants.

Table 2 Medication-related characteristics of participants ( $N=337)$, Debre Tabor General Hospital, 2015

\begin{tabular}{lcl}
\hline Variable & Frequency & Percent \\
\hline Number of medications & & \\
$\quad<2$ & 112 & 33.2 \\
$\geq 2$ & 225 & 66.8 \\
Knowledge about HTN and its treatment & \\
$\quad$ Good & 262 & 77.7 \\
$\quad$ Poor & 75 & 22.3 \\
Level of BP control & & \\
$\quad$ Control & 143 & 42.4 \\
Uncontrolled & 194 & 57.6 \\
\hline
\end{tabular}

Abbreviations: HTN, hypertension; BP, blood pressure.

\section{Proportion of good medication adherence}

The overall proportion of good medication adherence was $75.1 \%$ (95\% CI: 70.3, 79.5), and it was higher among urban resident patients than among rural dwellers.

\section{Factors associated with medication adherence}

The multivariable binary logistic regression analysis showed that urban residence, taking less than two drugs per day, and having knowledge about HTN and its treatment were positively and significantly associated with good medication adherence, whereas age $>60$ years was negatively and significantly associated with good medication adherence.

In this study, patients who lived in urban areas were two times (adjusted odd ratio $[\mathrm{AOR}]=2.10,95 \% \mathrm{CI}: 1.15,3.85$ ) as likely to adhere to their antihypertensive medication therapy compared to those who lived in rural areas. Hypertensive patients who took less than two drugs a day were three times (AOR=3.04, 95\% CI: 1.53, 6.06) as likely to adhere to their antihypertensive medication compared to patients who took two or more drugs. Hypertensive patients who had good knowledge of HTN and its treatment were approximately nine times (AOR $=8.86,95 \% \mathrm{CI}: 4.67,16.82)$ as likely to adhere to their antihypertensive medication/s as compared to those who had poor knowledge. Patients older than 60 years were $67 \%$ (AOR $=0.33,95 \%$ CI: $0.11,0.98)$ less likely to adhere to their antihypertensive medication/s as compared to younger patients (Table 3).

\section{Discussion}

Patients' adherence to their antihypertensive medication/s has paramount importance for preventing its sequelae or associated morbidities and deaths. This study revealed that threequarters $(75.1 \%)$ of hypertensive patients had good adherence to their medication therapy. This implies that one out of four patients were nonadherent to their medication therapy.

This finding was in line with those of studies done among Africa Americans $(77.4 \%)^{28}$ and in northern Ethiopia (73.6\%). ${ }^{29}$ It was higher than those of studies done in the rural-urban slum areas of Hyderabad (60.6\%), ${ }^{30}$ North India (57.2\%), ${ }^{31}$ Congo-Brazzaville (67.5\%), ${ }^{32}$ a tertiary hospital in Nigeria (44.7\%), ${ }^{33}$ Tikur Anbessa Specialized Hospital in Addis Ababa (69.2\%), ${ }^{23}$ and Adama Referral Hospital in Ethiopia (59.5\%). ${ }^{34}$ However, it was lower than that of a study done on Swedish adults $(87.3 \%) .{ }^{35}$ The possible reason for the difference might be variations in the methods of 
Table 3 Bivariate and multivariable logistic regression analyses of factors associated with medication adherence

\begin{tabular}{|c|c|c|c|c|}
\hline \multirow[t]{2}{*}{ Variable } & \multicolumn{2}{|c|}{ Medication adherence level, $\mathbf{n}(\%)$} & \multirow[t]{2}{*}{ COR $(95 \% \mathrm{Cl})$} & \multirow[t]{2}{*}{ AOR $(95 \% \mathrm{Cl})$} \\
\hline & Yes & No & & \\
\hline \multicolumn{5}{|c|}{ Age (years) } \\
\hline $18-40$ & $29(82.9)$ & $6(17.1)$ & 1 & I \\
\hline $4 I-60$ & $127(78.9)$ & $34(21.1)$ & $0.77(0.30,2.01)$ & $0.67(0.22,2.03)$ \\
\hline$>60$ & $97(68.8)$ & $44(31.2)$ & $0.46(0.18,1.18)$ & $0.33(0.11,0.98)^{*}$ \\
\hline \multicolumn{5}{|l|}{ Residence } \\
\hline Urban & $183(78.5)$ & $50(21.5)$ & $1.83(1.10,3.04)^{*}$ & $2.10(1.15,3.85)^{*}$ \\
\hline Rural & $70(67.3)$ & $34(32.7)$ & 1 & I \\
\hline \multicolumn{5}{|c|}{ Alcohol drinking status } \\
\hline Yes & $26(65.0)$ & $14(35.0)$ & $0.57(0.28,1.16)$ & $0.60(0.25, I .4 I)$ \\
\hline No & $227(76.4)$ & $70(23.6)$ & 1 & I \\
\hline \multicolumn{5}{|l|}{ Asthma } \\
\hline Yes & $14(53.8)$ & $12(46.2)$ & $0.35(0.16,0.79)^{*}$ & $0.54(0.2 \mathrm{I}, \mathrm{I} .4 \mathrm{I})$ \\
\hline No & $239(76.8)$ & $72(23.2)$ & 1 & I \\
\hline \multicolumn{5}{|c|}{ Diabetes mellitus } \\
\hline Yes & $53(81.5)$ & $12(18.5)$ & $1.59(0.80,3.15)$ & $1.89(0.85,4.19)$ \\
\hline No & $200(73.5)$ & $72(26.5)$ & 1 & I \\
\hline \multicolumn{5}{|c|}{ Number of medications per day } \\
\hline$<2$ & $92(82.1)$ & $20(17.9)$ & $\mathrm{I} .83(\mathrm{I} .04,3.2 \mathrm{I})^{*}$ & $3.04(1.53,6.06)^{*}$ \\
\hline$\geq 2$ & $161(71.6)$ & $64(28.4)$ & 1 & I \\
\hline \multicolumn{5}{|c|}{ Knowledge about HTN and its treatment } \\
\hline Good & $220(84.0)$ & $42(16.0)$ & $6.67(3.80,11.70)^{* *}$ & $8.86(4.67,16.82)^{* *}$ \\
\hline Poor & $33(44.0)$ & $42(56.0)$ & I & I \\
\hline
\end{tabular}

Notes: ${ }^{*} p<0.05$. ${ }^{*} p<0.001$. Hosmer and Lemeshow test $=0.604$.

Abbreviations: $\mathrm{COR}$, crude odds ratio; $\mathrm{Cl}$, confidence interval; $\mathrm{AOR}$, adjusted odd ratio; HTN, hypertension.

measurement used to assess medication adherence among different population groups. Another possible reason could be variations in the levels of education of participants; that is, almost half of the respondents in this study were illiterate.

In this study, a significant association was observed between patient residence and medication adherence. Hypertensive patients who lived in urban areas were two times as likely to adhere to their medication therapy as compared to those who lived in rural areas. This is in line with a study conducted in northern Ethiopia. ${ }^{29}$ This might be due to the fact that rural residents are basically farmers too busy plowing and weeding to come to the health facility for their pills. They might even forget to take their medication in time. Differences in educational levels and access to media might also be the possible reasons for the difference, which can be explained by the fact that urban dwellers have access to different media and are more likely to be more educated than the rural population.

The number of drugs that patients were taking had a significant association with medication adherence. This study revealed that patients who took a single drug per day were three times as likely to adhere to their prescribed drugs as compared to patients who took multiple drugs per day. This finding is in line with those of studies done on African Americans, ${ }^{28}$ in rural-urban slum areas of Hyderabad, ${ }^{30}$ in North India, ${ }^{31}$ in a tertiary hospital in Nigeria, ${ }^{33}$ and on Swedish adults. ${ }^{35}$ This might be due to the fact that when the number of drugs patients took increased, they might be confused (suffer from complex treatment regimens) about taking the right drug at the right time, which decreases adherence to medications. Additionally, when the pill burden increases, the cumulative side effect of the drugs, especially gastrointestinal upset, may hinder the appropriate use of the prescribed drugs.

Hypertensive patients who had good knowledge about HTN and its treatment were nine times as likely to adhere to their medication therapy as compared to patients who had poor knowledge. This finding is supported by studies done in Congo-Brazzaville, ${ }^{32}$ a tertiary hospital in Nigeria, ${ }^{33}$ and Adama Referral Hospital in Ethiopia. ${ }^{34}$ The possible reason may be that knowledgeable patients are more conscious of the consequences of not taking drugs appropriately.

Hypertensive patients $>60$ years were $67 \%$ less likely to adhere to their antihypertensive medication therapy as compared to younger respondents. This is consistent with findings of studies done on African Americans, ${ }^{28}$ in rural-urban slum areas of Hyderabad, ${ }^{30}$ and in Congo-Brazzaville. ${ }^{32}$ The possible reason might be age-related cognitive impairment, which is usually seen in older people. 
Use of self-report, which has the disadvantage of recall bias, as the only method of measuring adherence is the limitation of the study.

\section{Conclusion}

A high proportion of hypertensive patients have poor medication adherence. Urban residents, taking a single drug per day, and having knowledge about HTN and its treatment were factors and significantly associated with medication adherence, whereas being $>60$ years was negatively associated with medication adherence. Improving the knowledge of hypertensive patients regarding the disease and the need for adherence to medication/s by giving more emphasis to old age and rural patients is very crucial for increasing patient adherence to antihypertensive therapy.

\section{Acknowledgments}

We would like to express our heartfelt gratitude to the University of Gondar, Institute of Public Health, for giving us the chance to conduct this research. Our acknowledgment extends to all study participants for their time and willingness to respond and to data collectors and the supervisor for their friendly work. Finally, we would like to thank Sr. Mekides Abate Endalew for her unreserved support throughout our project; without her effort, the project would not be fruitful at all.

\section{Author contributions}

All authors contributed toward data analysis, drafting and critically revising the paper and agree to be accountable for all aspects of the work.

\section{Disclosure}

The authors report no conflicts of interest in this work.

\section{References}

1. Vijver SVD, Akinyi H, Oti S, et al. Status report on hypertension in Africa - consultative review for the 6th session of the African union conference of ministers of health on NCD's. Pan Afr Med J. 2013;16:38.

2. World Health Organization. A Global Brief on Hypertension: Silent Killer, Global Public Health Crisis. World Health Day; Geneva, Switzerland, 2013.

3. Your Guide to Lowering Blood Pressure. National Heart, Lung, and Blood Institute. 2003.

4. Maryon-Davis A, Press V. Easing the Pressure: Tackling Hypertension. National Heart Forum; London, UK, 2005.

5. JNC-8 New Guidelines. Finally Let the Controversies Begin. 2014.

6. World Health Organization. Attaining the Nine Global Noncommunicable Diseases Targets; a Shared Responsibility. Global Status Report on NCDs. 2014.

7. World Health Organization. Global Status Report on Noncommunicable Diseases 2010. Geneva: World Health Organization; 2011.
8. World Health Organization. Noncommunicable Diseases: A Major Health Challenge of the 21st Century. World Health Statistics; Geneva, Switzerland, 2012.

9. Federal Ministry of Health. Health and Health Related Indicators. Addis Ababa, Ethiopia: Federal Ministry of Health; 2010.

10. Heart Foundation. Assessing and Managing Raised Blood Pressure in Adults. Heart Foundation; Australia, 2010.

11. Duncana P, Howeab L, Manakusac Z, Purdya S. Determinants of blood pressure control in rural KwaZulu-Natal, South Africa. SAfr Fam Pract. 2014;56(6):297-304.

12. Ramli A, Ahmad NS, Paraidathathu T. Medication adherence among hypertensive patients of primary health clinics in Malaysia. Patient Prefer Adherence. 2012;6:613-622.

13. Ambaw AD, Alemie GA, W/Yohannes SM, Mengesha ZB. Adherence to antihypertensive treatment and associated factors among patients on follow up at University of Gondar Hospital, northwest Ethiopia. BMC Public Health. 2012;12:282.

14. Babiker FA, Elkhalifa LA, Moukhyer ME. Awareness of hypertension and factors associated with uncontrolled hypertension in Sudanese adults. Cardiovasc J Afr. 2013;24(6):208-212.

15. Dzudie A, Kengne AP, Muna WFT, et al; CCS Investigator Group. Prevalence, awareness, treatment and control of hypertension in a self selected Sub-Saharan African urban population: a cross-sectional study. BMJ Open. 2012;2(4):e001217.

16. Lichisa GC, Tegegne GT, Gelaw BK, Defersha AD, Woldu MA, Linjesa $\mathrm{JL}$. Blood pressure control and its contributing factor among ambulatory hypertensive patients in Adama Hospital medical college, East Shoa, Adama, Ethiopia. Int J Pharm Biol Sci Res Dev. 2014;2(7):1-15.

17. Rachel G, Bastos B, Nereida Kilza da Costa L. Adherence rates of hypertension treatment in Brazil and around the world. Rev Bras Hipertens. 2006;13(1):35-38.

18. Boima V, Ademola AD, Odusola AO, et al. Factors associated with medication nonadherence among hypertensives in Ghana and Nigeria. Int J Hypertens. 2015;2015:8.

19. Awoke A, Awoke T, Alemu S, Megabiaw B. Prevalence and associated factors of hypertension among adults in Gondar, northwest Ethiopia: a community based cross-sectional study. BMC Cardiovasc. 2012; 12:113.

20. Bonsa F, Gudina EK, Hajito KW. Prevalence of hypertension and associated factors in Bedele town, southwest Ethiopia. Ethiop J Health Sci. 2014;24(1):21-26.

21. Gudina EK, Michael Y, Assegid S. Prevalence of hypertension and its risk factors in southwest Ethiopia: a hospital-based cross-sectional survey. Integr Blood Press Control. 2013;6:111-117.

22. Helelo TP, Gelaw YA, Adane AA. Prevalence and associated factors of hypertension among adults in Durame town, Southern Ethiopia. PLoS One. 2014;9(11):e112790.

23. Hareri HA, Abebe M. Assessments of adherence to hypertension medications and associated factors among patients attending Tikur Anbessa specialized hospital renal unit, Addis Ababa, Ethiopia. Int J Nurs Sci. 2013;3(1):1-6.

24. World Health Organization. The WHO STEPwise Approach to Chronic Disease Risk Factor Surveillance (STEPS). Geneva, Switzerland: World Health Organization.

25. Morisky DE, Green LW, Levine DM. Concurrent and predictive validity of a self-reported measure of medication adherence and long-term predictive validity of blood pressure control. Med Care. 1986;24(1):67-74.

26. Morisky DE, Malotte CK, Choi P, et al. A patient education program to improve adherence rate with antituberculosis drug regimens. Health Educ Q. 1990;17(3):253-268.

27. Morisky DE, DiMatteo MR. Improving the measurement of self-reported medication nonadherence: final response. J Clin Epidemiol. 2011;64(3): $258-263$.

28. Solomon A, Schoenthaler A, Seixas A, Ogedegbe G, Jean-Louis G, Lai $D$. Medication routines and adherence among hypertensive African Americans. J Clin Hypertens (Greenwich). 2015;17(9):668-672. 
29. Ali MA, Bekele ML, Teklay G. Antihypertensive medication nonadherence and its determinants among patients on follow up in public hospitals in Northern Ethiopia. Int J Clin Trials. 2014;1(3):95-104.

30. Rao BB, Kabra PR, Sreedhar M. Factors associated with adherence to antihypertensive treatment among hypertensive persons in urban slum area of Hyderabad. Indian J Basic Appl Med Res. 2014;4(1):471-477.

31. Ahmad S. Assessment of adherence to antihypertensive treatment among patients attending a health care facility in North India. Int $J$ Res Med Sci. 2015;4(1):117-124.

32. Nsitou BM, Ikama MS, Drame B, Kaboru BB. Patients-related predictors of poor adherence to antihypertensive treatment in Congo-Brazzaville: a cross-sectional study. Global J Med Pub Health. 2015;2(5):1-9.
33. Ajayi EA, Adeoti AO, Ajayi IA, Ajayi AO, Adeyeye VO. Adherence to antihypertensive medications and some of its clinical implications in patients seen at a tertiary hospital in Nigeria. J Dent Med Sci. 2013;8(4): 36-40.

34. Hareri HA, Gedefaw M, Simeng B. Assessment of prevalence and associated factors of adherence to antihypertensive agents among adults on follow up in Adama Referal hospital, East Shoa, Ethiopiacross sectional study. Int J Curr Microbiol Appl Sci. 2014;3(1) 760-770.

35. Hedna K, Hakkarainen KM, Gyllensten H, et al. Adherence to antihypertensive therapy and elevated blood pressure: should we consider the use of multiple medications? PLoS One. 2015;10(9):e0137451.
Integrated Blood Pressure Control

\section{Publish your work in this journal}

Integrated Blood Pressure Control is an international, peer-reviewed open-access journal focusing on the integrated approach to managing hypertension and risk reduction. Treating the patient and comorbidities together with diet and lifestyle modification and optimizing healthcare resources through a multidisciplinary team approach constitute key

\section{Dovepress}

features of the journal. This journal is indexed on American Chemical Society's Chemical Abstracts Service (CAS). The manuscript management system is completely online and includes a very quick and fair peerreview system, which is all easy to use. Visit http://www.dovepress.com/ testimonials.php to read real quotes from published authors.

Submit your manuscript here: https://www.dovepress.com/integrated-blood-pressure-control-journal 